\title{
Retracted: A Newborn with Genital Ambiguity, 45,X/46,XY Mosaicism, a Jumping Chromosome $Y$, and Congenital Adrenal Hyperplasia
}

\author{
Case Reports in Endocrinology
}

Received 31 January 2022; Accepted 31 January 2022; Published 22 February 2022

Copyright (c) 2022 Case Reports in Endocrinology. This is an open access article distributed under the Creative Commons Attribution License, which permits unrestricted use, distribution, and reproduction in any medium, provided the original work is properly cited.

At the request of the authors, the article titled "A Newborn with Genital Ambiguity, 45,X/46,XY Mosaicism, a Jumping Chromosome Y, and Congenital Adrenal Hyperplasia" [1] has been retracted. The article stated that "Full written consent has been obtained from the parents of the patient for the publication of this paper." However, the parents have since stated that they did not understand the full scope of this disclosure and have now withdrawn their consent.

\section{References}

[1] L. Zhang, L. D. Cooley, S. R. Chandratre, A. Ahmed, and J. D. Jacobson, "A newborn with genital ambiguity, 45,X/46,XY mosaicism, a jumping chromosome $\mathrm{Y}$, and congenital adrenal hyperplasia," Case Reports in Endocrinology, vol. 2013, Article ID 747898, 6 pages, 2013. 


\title{
A Newborn with Genital Ambiguity, 45,X/46,XY Mosaicism, a Jumping Chromosome Y, and Congenital Adrenal Hyperplasia
}

\author{
Lei Zhang, ${ }^{1}$ Linda D. Cooley, ${ }^{1}$ Sonal R. Chandratre, ${ }^{2}$ Atif Ahmed, ${ }^{3}$ and Jill D. Jacobson ${ }^{2}$ \\ ${ }^{1}$ Cytogenetics Laboratory, Department of Pathology and Laboratory Medicine, Children's Mercy Hospitals and Clinics, \\ University of Missouri-Kansas City School of Medicine, Kansas City, MO 64108, USA \\ ${ }^{2}$ Division of Endocrinology and Diabetes, Department of Pediatrics, Children's Mercy Hospitals and Clinics, \\ University of Missouri-Kansas City School of Medicine, Kansas City, MO 64108, USA \\ ${ }^{3}$ Department of Pathology and Laboratory Medicine, Children's Mercy Hospitals and Clinics, \\ University of Missouri-Kansas City School of Medicine, Kansas City, MO 64108, USA
}

Correspondence should be addressed to Jill D. Jacobson; jjacobson@cmh.edu

Received 23 August 2013; Accepted 12 September 2013

Academic Editors: E. Hershkovitz and R. Swaminathan

Copyright (C) 2013 Lei Zhang et al. This is an open access article distributed under the Creative Commons Attribution License, which permits unrestricted use, distribution, and reproduction in any medium, provided the original work is properly cited.

At the request of the authors, the article titled A Newborn with Genital Ambiguity, 45,X/46,XY Mosaicism, a Jumping Chromosome Y, and Congenital Adrenal Hyperplasia has been retracted. The article stated that Full written consent has been obtained from the parents of the patient for the publication of this paper. However, the parents have since stated that they did not understand the full scope of this disclosure and have now withdrawn their consent. 